\title{
Artificial Neural Network Modeling To Predict And Optimize Phenolic Acids Production From Callus Culture of Lactuca Undulata
}

\section{Rezvan Ramezannejad}

Golestan University

Morteza Mofid Bojnoordi

Golestan University

Mohammad Armin

Islamic Azad University, Sabzevar, Iran

Mahnaz Aghdasi ( $\square$ aghdasi1346@gmail.com )

Golestan University

\section{Research Article}

Keywords: Lactuca undulata, cichoric acid, Artificial Neural Networks, Callus, Feed-forward multilayer perceptron network

Posted Date: September 20th, 2021

DOl: https://doi.org/10.21203/rs.3.rs-750673/v1

License: (9) This work is licensed under a Creative Commons Attribution 4.0 International License. Read Full License 


\section{Abstract}

The present study aims to model and optimize phenolic acids productions from Lactuca undulate root and leaf-derived callus using the feed-forward Artificial Neural Network (ANN) model. For this purpose, the effect of different concentrations $(0,0.1,0.5,1$, and $2 \mathrm{mg} / \mathrm{l})$ of Kin in combinations with or without 2,4-D and/or NAA was investigated on callus induction and phenolic acids production. A multi-layer perceptron ANN was applied to correlate the output parameters (cichoric acid, chlorogenic acid and caffeic acid contents) to input (Kin, 2,4-D and NAA) training parameters. A single hidden layer with 5, 10, $15,20,25,30,35$ and 40 neurons was used to optimize ANN architecture. Sum squared error (SSE), Relative Error $(\mathrm{RE})$ and correlation factor $\left(\mathrm{R}_{2}\right)$ were applied to identify the performance of ANN models. According to the obtained data, the feed-forward neural network with tangent-sigmoid (3-30-1), tangenttangent (3-15-1) and tangent-tangent (3-35-1) activation function was found as the best model to predict cichoric acid, chlorogenic acid and caffeic acid production from leaf-derived callus, respectively. Meanwhile, ANN with activation function of tangent-tangent (3-20-1), tangent-tangent (3-25-1) and sigmoid-sigmoid (3-20-1) were the most effective models to predict the amount of cichoric acid, chlorogenic acid and caffeic acid from root-derived callus, respectively. In the current study, there was a strong correlation between experimental and predicted data. These results demonstrated that the selected ANN model could predict the effects of plant growth regulators on phenolic acids production using callus culture method.

\section{Introduction}

Lactuca undulata is an annual plant belonging to the Asteraceae family. The most critical components of this species are phenolic acids including caffeic acid, cichoric acid and chlorogenic acid (Ramezannejad et al., 2019b). Cichoric acid is a primary caffeic acid derivative and identified in various plants, particularly the Asteraceae family (Liu et al., 2012; Sytar et al. 2018). This metabolite is a valuable industrial medicinal compound with many potential benefits for human health and can exert the effects of anti-cancer, anti-ADIS, and anti-diabetes, along with others (Chappel and Hahlbrock 1984; Dixon 1995). Our previous study indicated that stems of $L$. undulata had the highest cichoric acid content $(2.31 \mathrm{mg} / \mathrm{g}$ DW) during reproductive stage (Ramezannezhad et al. 2019). Various factors such as plant species, developmental stage, plant age, and drying methods can affect cichoric acid production (Lee and Scagel 2013).

Caffeic acid, as a precursor of cichoric acid, is known for its immune-stimulatory activities and anti-tumor properties (Chung et al. 2004). Like cichoric acid, chlorogenic acid is a caffeic acid derivative that is known as a potent antioxidant. In addition, chlorogenic acid can reduce the risks of type 2 diabetes, Alzheimer's, and cardiovascular diseases (Farah et al. 2008).

Callus culture is a proper method to induce and enhance the production of secondary metabolites in different plants (Vanisree et al. 2004). Various factors such as genotype, plant growth regulators (PGRs), medium culture, type and age of explant, and environmental conditions can affect the callus production 
(Effert 2019). So far, few reports were published concerning cichoric acid production in in vitro conditions in different plant species, such as Echinacea purpurea (Manayi et al. 2015, Ramezannezhad et al. 2019a). However, no reports have been published on the tissue culture of L. undulata.

Nowadays, data processing technology allows the modeling of biological processes by various softwares such as Artificial Neural Network (ANN) (Kerdpiboon et al. 2006). ANN is a flexible mathematical tool that can interconnect artificial neurons and identify the complex nonlinear relationships between input and output variables. When it is difficult to describe the characteristics of the investigated processes by mathematical equations, applying ANN models is valuable and efficient. By using ANN, we can map input and output data without knowing the relationship between them. Also, ANN has self-learning, which is essential for predicting the process (Aghbashlo et al. 2012). ANN has successfully been applied in the tissue culture to optimize culture conditions and produce various secondary Metabolites. Arab et al (2016) used ANN to model and optimize a new culture medium for in vitro rooting of G×N15 rootstock. So far, the ANN was used to determine the three marker compounds (cichoric acid, chlorogenic acid, and echinacoside) in Echinacea commercial formulations (Agatonovic-Kustrin et al. 2013). However, there is no study available in the literature concerning the use of ANN for modeling phenolic acids production in L. undulata. For the first time, the present study investigates the impact of three PGRs: 2,4-D, NAA, and Kin on cichoric acid, chlorogenic acid, and caffeic acid production in callus culture of $L$. undulata, as well as to model the process variables by ANNs. The present study results are useful as a model system to exploit tissue cultures for commercial production of pharmaceutical compounds using large bioreactors.

\section{Material And Methods}

\section{Plant Material}

In this work, Lactuca undulata was collected from the Binalood Mountains in the northeast of Iran (36 ' $\left.321^{\prime \prime} 6^{\circ} \mathrm{N}, 59^{\prime} 40^{\prime \prime} 53^{\circ} \mathrm{E}\right)$, identified by plant Science Institute Herbarium, Ferdowsi University, Mashhad, Iran and authenticated under number 6962.

\section{Seed Sterilization}

Seeds were washed with tap water and sterilized by soaking $70 \%$ ethanol for 30 seconds. Then seeds were sterilized 5 minutes in $7 \%(\mathrm{v} / \mathrm{v})$ commercial bleach followed by five times washing in sterile distilled water. Sterilized seeds were plated on agar solidified 1/2 MS medium (Murashige and Skoog 1962) supplemented with $15 \mathrm{~g} / \mathrm{L}$ sucrose and $8 \mathrm{~g} / \mathrm{L}$ agar at pH 5.7 and transferred to a growth chamber at 25 ${ }^{\circ} \mathrm{C}$ under a 16-h-light/8-h-dark photoperiod for two months.

\section{Callus Induction}

Root and leaf explants were obtained from 2 months old sterile seedlings. The selected explants were cultured on $1 / 2 \mathrm{MS}$ medium supplemented with different concentrations $(0,0.1,0.5,1$, and $2 \mathrm{mg} / \mathrm{L})$ of Kin in combination with 2,4-D and or NAA. The cultures were incubated in a growth chamber at $25 \pm 2^{\circ} \mathrm{C}$ 
under a 16-h-light/8-h-dark photoperiod. Three replications, arranged in a completely randomized design, were prepared for each treatment. The callus was sub-cultured to the fresh medium every two weeks. After eight weeks, the percentage of callus production, total phenol, caffeic acid, cichoric acid, and chlorogenic acid amount was measured.

\section{Determination of Total Phenol Content (TPC)}

Total phenol content was measured based on the folin-ciocalteu method, as described by Meda et al. 2005. In brief, $0.1 \mathrm{gr}$ dried powdered samples were dissolved in $80 \%$ aqueous methanol $(20 \mathrm{ml})$ and kept at room temperature for 48 hours. The mixture was centrifuged at $13000 \mathrm{~g}$ for 10 minutes at $0^{\circ} \mathrm{C}$. The supernatant was used for determination of total phenol content.

\section{Extraction of Caffeic Acid Derivatives}

Dried callus $(0.01 \mathrm{~g})$ was extracted in $10 \mathrm{ml}$ of $20 \%(\mathrm{~V} / \mathrm{V})$ acetonitrile in the complete darkness for $24 \mathrm{~h}$. The mixture was centrifuged at $13000 \mathrm{~g}$ for $10 \mathrm{~min}$. The supernatant was used to determine caffeic acid derivatives content (Luo et al. 2006).

\section{HPLC Analysis}

Caffeic acid and its derivatives contents were determined by an HPLC method using a eurospher C18 (250 $\times 4 \mathrm{~mm})$ column and a UV/VIS detector. The mobile phase was composed of absolute acetonitrile (Phase $\mathrm{A}$ ) and 1\% aqueous phosphoric acid ( $\mathrm{v} / \mathrm{v}$ ) (Phase B). The constant flow rate was $1 \mathrm{ml} / \mathrm{min}$. Caffeic acid and chlorogenic acid were detected on $278 \mathrm{~nm}$, while cichoric acid were monitored at 330 $\mathrm{nm}$. The volume of injection was $20 \mu \mathrm{L}$ of each sample. The compounds in each sample were calculated using the standard curve.

\section{Statistical Analyze}

Analysis of variances (ANOVA) was made by using SAS-software Version 9.1. Differences between means were reported by Duncan's multiple range test $(p \leq 0.05)$.

In order to measure the levels of cichoric acid, chlorogenic acid, and caffeic acid, we selected concentrations of PGRs, which caused the highest production of TPC in leaf and root-derived callus. Our previous study results showed a significant positive correlation between TPC and the production of cichoric acid, chlorogenic acid, and caffeic acid (Ramezannejad et al. 2020). For this purpose, the slicing interaction method was used to analyze the effect of PGR concentrations on total phenol content (Nouri et al. 2006; Khaliliaqdam et al. 2012).

\section{Modeling of ANN}

In the present study, the applied ANN model is a feed-forward multiplayer perceptron designed by SPSS software (version 27). ANN is a powerful tool for recognizing, function fitting, and clustering of data. It 
comprises units including input/output, weights, hidden layer, and activation function. The mathematical explanation of the fundamental ANN is as follows:
1. $0=f(w x+$ bias $)$
2. $W=w_{1}, w_{2}, \ldots, w_{n}$,
3. $X=x_{1}, x_{2}, \ldots, x_{n}$.

Weights (W) and inputs (X) are expressed by equations (2) and (3), respectively. The following equation obtains the transfer function of the ANN:

$$
\text { (4) } y_{i}=\sum_{i=1}^{p} \mathrm{~W}_{\mathrm{ij}} \mathrm{X}_{\mathrm{i}}+\mathrm{b}_{\mathrm{j}}
$$

In the formula, $W_{i j}$ is the weight index of neuron $\mathrm{i}$ connected to neuron $\mathrm{j}$. $\mathrm{p}$ represents the number of inputs for each neuron, and $b_{j}$ represents the bias value of neuron $j$ (Salehi et al. 2012).

If the sigmoid function is used as the activation function, the network output is as follows:

(5) $\operatorname{sig}=\frac{1}{1+e^{-x}}$

The ANN layout, in this study, consists of three inputs and one output, and a single hidden layer. Inputs include concentrations of Kin, 2,4-D, and NAA, and outputs comprise cichoric acid, chlorogenic acid and caffeic acid. In order to simplify the analysis, we analyzed each of the output variables separately. Figure 1 presents the proposed ANN model with three inputs and one output with a hidden layer in leaf and rootderived callus. A single hidden layer with a combination of two activation functions (sigmoid and tangent hyperbolic) for hidden and output layers was used to obtain the best value of network performance. Studied models, including sigmoid-sigmoid, sigmoid-tangent, tangent-tangent, and tangent-sigmoid and 10 different neuron numbers $(5,10,15,20,25,30,35,40)$, were designed to predict the phenolic acids production in leaf and root-derived callus.

Data were classified into two categories to develop the ANN model: training (70\%) and testing (30\%). $\mathrm{R}^{2}$ (the coefficient of explanation) and relative error (RE) were used as the main indicators to determine the best layout of ANN.

The $\mathrm{R}^{2}$ and MRE criterions are defined as 7 and 8 equations, respectively: 
(7) $R^{2}=\frac{\sum_{i=1}^{n}\left(P_{A N N}-P_{E X P}\right)^{2}}{\sum_{i=1}^{n}\left(P_{A N N}-P m_{E X P}\right)^{2}}$

(8) $M R E=\sum_{i=1}^{n} \frac{\left(P_{A N N}-P_{E X P}\right)}{P_{E X P}} \times 100$

In the formula, the number of observations, $P_{A N N}$ the predicted data, $P_{E X P}$ the experimental data, and $P m_{E X P}$ the mean experimental data.

\section{Results And Discussion}

Callus induction: The leaf and root explants were cultured on $1 / 2$ MS medium supplemented with different concentrations of Kin either alone or in combination with 2,4-D and or NAA. After seven days, callus induction was observed in the margin of root and leaf explants treated with or without different concentrations of PGRs combinations. Callus induction was observed at a high frequency $(100 \%)$ in all treatments. In addition, the morphology of the leaf-derived callus was friable and light green, but rootderived callus was friable and cream (Fig. 2).

Total Phenol Content (TPC): Data from statistical analyses showed that the interaction

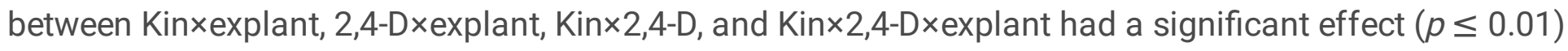
on the TPC of leaf and root-derived callus (Table 1A). The interaction slicing method was applied to analyze the effects of different concentrations of Kin in combination with 2,4-D and or NAA on the TPC. The obtained data revealed that $0.5,1$, and $2 \mathrm{mg} / \mathrm{L}$ Kin in combination with different concentrations of 2,4-D had a significant effect on TPC in both leaf and root-derived callus (Table 1B).

The results demonstrated that the effect of explant, Kin, and NAAx explant was not significant on TPC. However, the effects of other treatments were significant ( $\mathrm{s} \leq 0.01)$ on TPC (Table 2A). Interestingly, rootderived callus showed a significant increase $(p \leq 0.01)$ in TPC when grown in the medium supplemented with $0.5,1$, and $2 \mathrm{mg} / \mathrm{L}$ Kin in combination with different concentrations of NAA (Table 2B).

The comparison of means revealed that the highest TPC $(32.23 \mathrm{mg} / \mathrm{g} \mathrm{DW})$ was observed in leaf-derived callus grown on $1 / 2 \mathrm{MS}$ medium supplemented with the combination of $0.5,1 \mathrm{mg} / \mathrm{L} \mathrm{Kin}$, and 2,4-D, respectively. Meanwhile, the highest TPC $(35.5 \mathrm{mg} / \mathrm{g} \mathrm{DW})$ was observed in the root-derived callus, grown on $1 / 2$ MS medium containing 2, $2 \mathrm{mg} / \mathrm{L} \mathrm{Kin}$, and NAA (Table 3 ).

Up to now, several reports have been published to show the effect of PGRs on the phenolic acids production in different medicinal plants in tissue culture conditions. However, there is no report for the callus culture of $L$. undulata. Our previous research showed that TPC in different parts of $L$. undulata in the reproductive phase is as follows: stem>root>leave. But during the vegetative phase, there is no significant difference in the TPC between different organs of this species (Ramezannezhad et al. 2019b). Secondary metabolites biosynthesis depends on various factors such as plant species and developmental stages. Because of the role of Secondary metabolites in the plant life cycle and growth 
stages, the concentration and accumulation of these compounds vary in different plant organs (Cheynier et al. 2013; Jiang et al. 2013). It was reported that TPC reached the maximum level in many herbaceous plants during the flowering time (Ammar et al. 2012; Fernando et al. 2013; Feduraev et al. 2019). On one hand, similar results have been reported by Lannucci et al. (2013), who reported a correlation between concentrations of phenolic compounds and plant growth. On the other hand, the obtained results indicated that the type of PGRs has an effective role on TPC in callus derived from different explants. Aremu et al. (2015) demonstrated that cytokinin can affect the phenylpropanoids pathway, especially at molecular levels. Another report confirmed that NAA induces phenolic compounds metabolism pathways via binding with TIR1 (Auxin receptor) (Buer et al. 2006).

Phenolic acids contents: Cichoric acid, chlorogenic acid, and caffeic acid contents were measured in leaf and root-derived callus, which contained the highest TPC. These metabolites were identified in both root and leaf explant and their corresponding callus. The obtained results revealed that cichoric acid and chlorogenic acid contents in root explant were more than leaf explant. However, the leaf explant contained a higher amount of caffeic acid than the root explant (Fig. 2A-D). The amount of polyphenols (such as cichoric acid) depends on various parameters, including harvested organ, harvest time, plant species, plant age, climatic factors, growth conditions, and others (Lee and Scagel 2013). For example, Qu et al. (2005) reported that the amount of cichoric acid in roots and shoots of Echinacea purpurea ranged from 2.03 to $38.55 \mathrm{mg} / \mathrm{g}$ DW. On the contrary, Zolgharnein et al. (2010) reported that the cichoric acid content is about $1.50 \mathrm{mg} / \mathrm{g}$ DW in the same plant (Zolgharnein et al. 2010).

Leaf-derived callus showed the highest amount of cichoric acid (3.95 mg/g DW) when grown on $1 / 2 \mathrm{MS}$ medium supplemented with $0.5,1 \mathrm{mg} / \mathrm{L} \mathrm{Kin}$, and 2,4-D, respectively (Figure $2 \mathrm{~A}$ ). In contrast, cichoric acid amount increased to $4.59 \mathrm{mg} / \mathrm{g}$ DW in root-derived callus when grown on medium contained $2,2 \mathrm{mg} / \mathrm{L}$ Kin, and 2,4-D (Figure 2B).

On one hand, the obtained results showed that the amount of chlorogenic acid in root explant $(1.03 \mathrm{mg} / \mathrm{g}$ DW) was almost two times more than in leaf explant (0.58 mg/g DW) (Figure 2C-D). On the other hand, the highest amount of chlorogenic acid $(2.50 \mathrm{mg} / \mathrm{g} \mathrm{DW})$ was obtained by the treatment with $1,0.1 \mathrm{mg} / \mathrm{I}$ Kin, and 2,4-D, respectively (Figure $2 \mathrm{C}$ ). However, chlorogenic acid accumulation reached to $3.17 \mathrm{mg} / \mathrm{g}$ DW in root-derived callus when grown on the medium containing 2, 2 mg/ I Kin, and 2,4-D (Figure $2 \mathrm{D}$ ).

In addition, 0.5, $1 \mathrm{mg} / \mathrm{l} \mathrm{Kin}$, and 2,4-D were the most effective PGRs concentration for caffeic acid production $(24.23 \mathrm{mg} / \mathrm{g} \mathrm{DW}$ ) in leaf-derived callus (Figure $2 \mathrm{E})$. Interestingly, the highest amount of caffeic acid (13.23 mg/g DW) was recorded in root-derived callus when grown on the medium containing: 2, $2 \mathrm{mg} / \mathrm{l} \mathrm{Kin}$, and NAA (Figure 2F).

In spite of no published reports concerning $L$. undulata tissue culture, some reports demonstrated that the amount of phenolic acids in explant is higher than corresponding callus in different plant species (ButiucKeul et al. 2012). It seems that plant species, the age of explant or callus, and concentrations of applied PGRs play a vital role in phenolic acids production under tissue culture conditions. According to the current data, the effect of PGRs on the phenolic acids content in leaf and root-derived callus was 
different, and it can be due to the type and concentration of PGRs. Caffeic acid is produced via Phenylpropanoids biosynthesis pathways, and PGRs regulate the biosynthesis of phenolic acids (Buer et al. 2006). The authors also found that NAA is linked to TIR1 (Auxin receptor) and induces phenolic acids metabolism pathway. Our data revealed that the root explant of L.undulata contained higher cichoric acid and chlorogenic acid than leaf explant. Whereas it contained lower caffeic acid, compared to the leaf explant. It can be because converting caffeic acid to its derivative (cichoric acid and chlorogenic acid) in root explant is faster than leaf explant. Besides, caffeic acid conversion to cichoric acid and chlorogenic acid is done by two separate pathways (Buer et al. 2006). It is possible that in both leaf and root explant, caffeic acid is converted to cichoric acid rather than chlorogenic acid. Overall, the current results indicated that both leaf and root-derived callus accumulated a higher amount of cichoric acid, chlorogenic acid, and caffeic acid, compared to the corresponding explants.

\section{ANN modeling}

In this study, the ANN model has been applied to predict the effects of different concentrations of PGRs (Kin, 2,4-D and NAA) on the production of phenolic acids in leaf and root-derived callus from L.undulata. Based on the data obtained from the interaction slicing method, several concentrations of Kin, 2,4-D, and NAA were selected, which had the most stimulatory effect on the TPC in root and leaf-derived callus (Table 4).

Figure 3 reveals the value of experimental outputs (cichoric acid, chlorogenic acid, and caffeic acid production) versus its predicted values obtained from leaf and root-derived callus in the most effective models of ANN.

Some of the performance factors of the used models were summarized in table 5. The results showed that the tangent- sigmoid activation function-based neural network with 30 hidden layer neurons had the most accurate prediction for the cichoric acid content in leaf-derived callus. Meanwhile, the correlation factor $\left(R^{2}\right)$ between the experimental outputs and the predicted output by ANN was equal to 0.8733 (Figure. 3A). By contrast, tangent-tangent activation function-based neural network with 20 hidden layer neurons indicated the best prediction for the content of cichoric acid in root-derived callus with $\mathrm{R}^{2}$ value equal to 0.8035 (Figure $3 \mathrm{~B}$ ). The sum of the square error (SSE) and the relative error (RE) were very low in both structures. Therefore, the current models can be reliable for the dataset (Table 3).

The structure 3-15-1 showed the best prediction for chlorogenic acid content in leaf-derived callus when tangent-tangent activation function was used in the hidden and output layer, respectively (Table 5). When, the experimental output variables were plotted against ANN-predicted output variables (Figure 3C), the value of $R^{2}$ between those values were 0.6838 . In contrast, the structure of 3-25-1 with tangenttangent activation functions was determined as the best model for predicting the amount of chlorogenic acid in root-derived callus (Table 5). The correlation between the experimental value of the variables and the ANN-predicted values of the output variables is shown in Figure 4D. According to this plotted curve, R2 is 0.975 and it demonstrates a strong correlation between the MLP-model outputs and experimental 
data. SSE and RE value of model was very low (Table 5). Therefore, the proposed model can predict the amount of chlorogenic acid in root-derived callus.

The optimized structure to predict caffeic acid values in leaf-derived callus is 3-25-1 with a tangenttangent activation function (Table 5). The obtained $R^{2}$ value was 0.72 (Fig. 3E). The best structure for the production of this metabolite in root-derived callus was sigmoid-sigmoid activation function-based neural network with 20 hidden layer neurons. In this case, the obtained $R^{2}$ value was 0.93 (Figure 3F). Value of SSE and RE were also very low (Table 5 ) and $\mathrm{R}^{2}$ datasets revealed a strong correlation between experimental and predicted data (Figure. 3F).

To date, there were no published reports for ANN modeling to predict phenolic acids production in L.undulata. However, few studies have predicted the production of phenolic acids using ANN in several plant species. Yu et al. (2019) used ANN to predict the optimized chlorogenic acid value in Lonicera japonica. Their results revealed that ANN modeling was successful in predicting the chlorogenic acid value. The constructed ANN indicated high $R^{2}$ values (0.9898). Also, ANN modeling was used for total phenol production in two species of bananas (cv. Musa nana and Musa cavendishii) (Guiné and Costa 2016). In this case, the sigmoid function was selected as the activation function. The results indicated that ANN could predict the experimental results. The highest error percentage between experimental and predicted data was less than 2.7 , and $R^{2}$ was equal to 0.95 . Xi et al. (2013) used ANN to optimize the extraction of polyphenols from tea. They used a feed-forward neural network with three input neurons, one hidden layer with eight neurons, and one output layer with a single neuron. The trained network showed the lowest MRE value (0.03) and maximum $\mathrm{R}^{2}$ value $(0.9571)$, which indicates a good agreement between the predicted value and the experimental value.

\section{Conclusion}

In the current study, ANN model was applied to predict the effect of PGRs (Kin, 2,4-D and NAA) on the production of cichoric acid, chlorogenic acid, and caffeic acid in leaf and root-derived callus of $L$. undulata. The ANN models were reliable, with values of $\mathrm{R} 2$ of $0.87,0.66$, and 0.70 for cichoric acid, chlorogenic acid, and caffeic acid contents in leaf-derived callus, respectively. On the other hand, the proposed models for the prediction of cichoric acid, chlorogenic acid, and caffeic acid in rootderived callus had $R_{2}$ value of $0.80,0.97,0.93$, respectively, which showed a good agreement between experimental data and ANN-predicted data. The developed model could be used to determine the optimum plant growth regulators concentration to obtain efficient phenolic acids production.

\section{Declarations}

\section{Acknowledgement}

We thank the Golestan University Deputy of Research and Office of High Education and Iran National Science Foundation for financial support. 


\section{Conflict of interest statement}

The authors declare that they have no conflicts of interest

\section{References}

1. Agatonovic-Kustrin S, Loescher CM, Singh R (2013) Quantification of phenylpropanoids in commercial echinacea products using TLC with video densitometry as detection technique and ANN for data modelling. Phytochem Anal 24:303-308

2. Aghbashlo M, Mobli H, Rafiee S, Madadlou A (2012) The use of artificial neural network to predict exergetic performance of spray drying process: A preliminary study. Comput Electron Agric 88:32-43

3. Ammar I, Ennouri M, Khemakhem B, Yangui T, Attia H (2012) Variation in chemical composition and biological activities of two species of Opuntia flowers at four stages of flowering. Ind Crop Prod $37: 34-40$

4. Arab M, Yadollahi A, Shojaeiyan A, Ahmadi H (2016) Artificial neural network genetic algorithm as powerful tool to predict and optimize in vitro proliferation mineral medium for $\mathrm{G} \times \mathrm{N} 15$ rootstock. Front Plant Sci 7:1526

5. Aremu AO, Plačková L, Gruz J, Bíba O, Šubrtová M, Novák O, Doležal K, Van Staden J (2015) Accumulation pattern of endogenous cytokinins and phenolics in different organs of 1-year-old cytokinin pre-incubated plants: implications for conservation. Plant Biol 17:1146-1155

6. Binns SE, Arnason JT, Baum BR (2002) Phytochemical variation within population of Ech inacea angustifolia (Astracea). Biochem Syst Ecol 30:837-854

7. Buer S, Poornima S, Muday G (2006) Ethylene modulates flavonoid accumulation and gravitropic responses in roots of Arabidopsis. Plant Physiol 4:1384-1396

8. Butiuc-Keul AL, Vlase L, Crăciunaş C (2012) Clonal propagation and production of cichoric acid in three species of Echinaceae. In Vitro Cell Devl Biol-Plant 48:249-258

9. Chappell J, Hahlbrock K (1984) Transcription of plant defence genes in response to UV light or fungal elicitor. Nature 311:76-78

10. Cheynier V, Comte G, Davies KM, Lattanzio V, Martens S (2013) Plant phenolics: Recent advances on their biosynthesis, genetics, and ecophysiology. Plant Physiol Biochem 72:1-20

11. Chung TW, Moon SK, Chang YC, Ko JH, Lee YC, Cho G, Kim SH, Kim JG, Kim CH (2004) Novel and therapeutic effect of caffeic acid and caffeic acid phenyl ester on hepatocarcinoma cells: complete regression of hepatoma growth and metastasis by dual mechanism. FASEB J 18:1670-1681

12. Dixon R, Paiva NL (1995) Stress-induced phenylpropanoid metabolism. Plant Cell 7:1085-1097

13. Effert T (2019) Biotechnology applications of plant callus cultures. Eng J 5:50-59

14. Farah A, Monteiro M, Donangelo CM, Lafay S (2008) Chlorogenic acids from green coffee extract are highly bioavailable in humans. Nutr J 138:2309-2315 
15. Fernando IDNS, Abeysinghe DC, Dharmadasa RM (2013) Determination of phenolic contents and antioxidant capacity of different parts of Withania somnifera (L.) Dunal. from three different growth stages. Ind Crop Prod 50:537-539

16. Feduraev P, Chupakhina G, Maslennikov P, Tacenko N, Skrypnik L (2019) Variation in Phenolic Compounds Content and Antioxidant Activity of Different Plant Organs from Rumex crispus L. and Rumex obtusifolius L. at Different Growth Stages. Antioxidants (Basel) 8:237-262

17. Guiné R, Costa DVTA (2016) Chemical Composition and Bioactive Compounds in Bananas and Postharvest Alterations. Bananas: Cultivation, Consumption and Crop Diseases. Chapter 2. Nova Science Publishers, Hauppauge, pp 27-68

18. Khaliliaqdam N, Soltani A, Mir-Mahmoodi T, Jadidi T (2012) Effect of leaf defoliation on some agronomical traits of corn. World Appl Sci J 20:545-548

19. Kerdpiboon S, William LK, Sakamon D (2006) Neural network prediction of physical property changes of dried carrot as a function of fractal dimension and moisture content. Int Food Res $\mathrm{J}$ 39:1110-1118

20. Jiang X, Liu Y, Li W, Zhao L, Meng F, Wang Y, Gao L (2013) Tissue-specific, development-dependent phenolic compounds accumulation profile and gene expression pattern in tea plant (Camellia sinensis). PLoS ONE 30:e62315

21. Lannucci A, Fragasso M, Platani C, Papa R (2013) Plant growth and phenolic compounds in the rhizosphere soil of wild oat (Avena fatua L.). Front Plant Sci 4:1-7

22. Lee J, Scagel CF (2013) Chicoric acid: chemistry, distribution, and production. Front Chem 1:1-17

23. Liu R, Li W, Sun LY, Liu CZ (2012) Improving root growth and cichoric acid derivatives production in hairy root culture of Echinacea purpurea by ultrasound treatment. Biochem Eng j 60:62-66

24. Luo X, Chen b, Ding L, Tang F, Yao S (2006) HPLC-ESI-MS analysis of vitamin B12 in food products and in multivitamins-multimineral tablets. Anal Chem Acta 562:185-189

25. Manayi A, Vazirian M, Saeidnia S (2015) "Echinacea purpurea: Pharmacology, phytochemistry and analysis methods. Pharmacognosy Reviews 9:63-72

26. Meda A, Euloge C, Romito LM, Millogo J, Nacoulma OG (2005) Determination of the total phenolic, flavonoid and proline contents in Burkina Fasan honey, as well as their radical scavenging activity. Food Chem 91:571-577

27. Nouri H, Fakher A, Jones CJFP (2006) Development of horizontal slice method for seismic stability analysis of reinforced slopes and walls. Geotext Geomembranes 24: 175-187

28. Qu L, Chen YC, Wang X, Scalzo R, Davis JM (2005) Patterns of variation in alkamides and cichoric acid in roots and aboveground parts of Echinacea purpurea (L.) Monench. HortScience 40:12391242

29. Ramezannezhad R, Aghdasi M, Fatemi M (2019a) Enhanced production of cichoric acid in cell suspension culture of Echinacea purpurea by silver nanoparticle elicitation. Plant Cell Tiss Org (PCTOC) 139:261-273 
30. Ramezannejad R, Aghdasi M, Fatemi M (2019b) An investigation on cichoric acid content and antioxidant activity in some Iranian native species compared to Echinacea purpurea L. in different developmental stages. Iranian J Med Arom Plants 34:909-923

31. Ramezannejad R, Aghdasi M, Fatemi M (2020) Application of response surface methodology for optimization of purple coneflower plant (Echinacea purpurea) tissue culture. J Plant Process Function 9:265-281

32. Salehi F, Razavi SMA (2012) Dynamic modeling of flux and total hydraulic resistance in nanofiltration treatment of regeneration waste brine using artificial neural networks. Desalin Water Treat 41:95-104

33. Sytar O, Hemmerich I, Zivcak M, Rauh C, Brestic M (2018) Comparative analysis of bioactive phenolic compounds composition from 26 medicinal plants. Saudi J Biol Sci 25:631-641

34. Vanisree M, Lee CY, Lo SF, Nalawade SM, Lin CY, Tsay HS (2004) Studies on the production of some important secondary metabolites from medicinal plants by plant tissue cultures. Bot Bull Acad Sin $45: 1-22$

35. Xi J, Xue Y, Xu Y, Shen Y (2013) Artificial neural network modeling and optimization of ultrahigh pressure extraction of green tea polyphenols. Food Chem 141:320-326

36. Yu HC, Huang SM, Lin WM, Kuo CH, Shieh CJ (2019) Comparison of artificial neural networks and response surface methodology towards an efficient ultrasound-assisted extraction of chlorogenic acid from Lonicera japonica. Molecules 24:2304. -2319

37. Zolgharnein J, Niazi A, Afiuni-Zadeh S, Zamani K (2010) Determination of Cichoric Acid as a Biomarker in Echinacea Purpurea Cultivated in Iran Using High Performance Liquid Chromatography. Chin Med 1:23-27

\section{Tables}

Table 1. Analysis of variance of the effect of explant type and PGRs (2,4-D ,Kin) concentrations on total Phenol content (TPC) of leaf and root-derived callus of Lactuca undulata (a), Slicing interaction for 
various concentrations of Kin in combination with each concentration of 2,4-D (b).

\begin{tabular}{|c|c|c|c|c|}
\hline & Source of variation & DF & \multicolumn{2}{|c|}{ TPC } \\
\hline & Explant & 1 & \multicolumn{2}{|c|}{$0.78^{\mathrm{ns}}$} \\
\hline & Kin & 4 & \multicolumn{2}{|c|}{3.24 ns } \\
\hline (A) & $2,4-\mathrm{D}$ & 4 & \multicolumn{2}{|c|}{$3.36^{\mathrm{ns}}$} \\
\hline & Kin $\times$ Explant & 4 & \multicolumn{2}{|c|}{$12.48^{* *}$} \\
\hline & 2,4-D $\times$ Explant & 4 & \multicolumn{2}{|c|}{$2.12^{* *}$} \\
\hline & $\operatorname{Kin} \times 2,4-D$ & 16 & \multicolumn{2}{|c|}{$6.67^{* *}$} \\
\hline & Kin $\times 2,4$-D $\times$ Explant & 16 & \multicolumn{2}{|c|}{$15.2^{* *}$} \\
\hline & Error & 100 & \multicolumn{2}{|c|}{3.24} \\
\hline & CV (\%) & - & \multicolumn{2}{|c|}{12.49} \\
\hline \multirow{7}{*}{ (B) } & \multicolumn{4}{|c|}{ Slicing interaction for various concentration of $\mathrm{Kin}$ in combination with each concentration of 2,4-D } \\
\hline & Kin concentration & & Leaf derived callus & root derived callus \\
\hline & $0 \mathrm{mg} / \mathrm{L}$ & 4 & $1.26^{\mathrm{ns}}$ & $3.08^{\mathrm{ns}}$ \\
\hline & $0.1 \mathrm{mg} / \mathrm{L}$ & 4 & $5.58^{\mathrm{ns}}$ & $8.63 \mathrm{~ns}$ \\
\hline & $0.5 \mathrm{mg} / \mathrm{L}$ & 4 & $23.59^{* *}$ & $12.5^{* *}$ \\
\hline & $1 \mathrm{mg} / \mathrm{L}$ & 4 & $24.03^{* *}$ & $20.07^{* *}$ \\
\hline & $2 \mathrm{mg} / \mathrm{L}$ & 4 & $18.19^{*}$ & $9.9^{* *}$ \\
\hline
\end{tabular}

$\mathrm{ns}^{*}$ and ${ }^{* *}$ shows not significant, $\mathrm{p}>0.05$ and $\mathrm{p}>0.01$

Table 2. Analysis of variance of the effect of explant type and PGRs (NAA, Kin) concentrations on total Phenol content of leaf and root-derived callus of Lactuca undulata (a), Slicing interaction for various concentrations of Kin in combination with each concentration of NAA (b).

\begin{tabular}{|c|c|c|c|c|}
\hline & Source of variation & DF & \multicolumn{2}{|c|}{ Total phenol content } \\
\hline & Explant & 1 & \multicolumn{2}{|c|}{$0.46^{\mathrm{ns}}$} \\
\hline & $\mathrm{K}$ in & 4 & \multicolumn{2}{|c|}{$8.52^{\mathrm{ns}}$} \\
\hline (A) & NAA & 4 & \multicolumn{2}{|c|}{$5.97^{\circ *}$} \\
\hline & Kin $\times$ Explant & 4 & \multicolumn{2}{|c|}{$13.99^{* *}$} \\
\hline & NAA $\times$ Explant & 4 & \multicolumn{2}{|c|}{$6.24^{n s}$} \\
\hline & $\mathrm{K}$ in $\times \mathrm{NAA}$ & 16 & \multicolumn{2}{|c|}{$8.27^{* *}$} \\
\hline & Kin $\times$ NAA $\times$ Explant & 16 & \multicolumn{2}{|c|}{$15.7^{* *}$} \\
\hline & Error & 100 & \multicolumn{2}{|c|}{8.73} \\
\hline & $\mathrm{CV}(\%)$ & - & \multicolumn{2}{|c|}{13.69} \\
\hline \multirow{7}{*}{ (B) } & \multicolumn{4}{|c|}{ Slicing interaction for various concentration of Kin in combination with each concentration of NAA } \\
\hline & Kin concentration & & Leaf derived callus & root derived callus \\
\hline & $0 \mathrm{mg} / \mathrm{L}$ & 4 & $1.5^{\mathrm{ns}}$ & $2.3^{\text {ns }}$ \\
\hline & $0.1 \mathrm{mg} / \mathrm{L}$ & 4 & $2.4^{\mathrm{ns}}$ & 4.9 ns \\
\hline & $0.5 \mathrm{mg} / \mathrm{L}$ & 4 & $15.7^{*}$ & $21.4^{*}$ \\
\hline & $1 \mathrm{mg} / \mathrm{L}$ & 4 & $14.5^{*}$ & $12.5^{\circ}$ \\
\hline & $2 \mathrm{mg} / \mathrm{L}$ & 4 & $19.3^{*}$ & $8.8^{\circ}$ \\
\hline
\end{tabular}

$\mathrm{ns}^{*}$ and ${ }^{* *}$ shows not significant, $\mathrm{p}>0.05$ and $\mathrm{p}>0.01$

Table 3. The effect of various concentrations of Kin in combination with each concentration of 2,4-D and or NAA on TPC (Total Phenol Content) of leaf and root-derived callus from Lactuca undulata. Column bars with different letters indicate significant differences at $p \leq 0.05$, according to the slicing interaction method. 


\begin{tabular}{|c|c|c|c|c|c|c|c|}
\hline \multicolumn{2}{|c|}{$\begin{array}{l}\text { PGR } \\
\text { (mg/L) }\end{array}$} & $\begin{array}{l}\text { Leaf derived } \\
\text { callus }\end{array}$ & $\begin{array}{l}\text { Root derived } \\
\text { callus }\end{array}$ & \multirow{2}{*}{\multicolumn{2}{|c|}{$\begin{array}{l}\text { PGR } \\
\text { (mg/L) } \\
\text { Kin } \\
2,4-D\end{array}$}} & \multirow[t]{2}{*}{$\begin{array}{l}\text { Leaf derived } \\
\text { callus }\end{array}$} & \multirow[t]{2}{*}{$\begin{array}{l}\text { Root derived } \\
\text { callus }\end{array}$} \\
\hline $\begin{array}{l}\text { Kin } \\
D\end{array}$ & $2,4-$ & & & & & & \\
\hline \multirow{5}{*}{0} & 0 & $11.02 \pm 0.44^{b}$ & $10.2 \pm 0.38^{b}$ & \multirow{5}{*}{0} & 0 & $8.89 \pm 0.44^{c}$ & $10.2 \pm 0.33^{d}$ \\
\hline & 0.1 & $11.02 \pm 0.5^{b}$ & $11.32 \pm 0.1^{a}$ & & 0.1 & $11.02 \pm 0.11^{b}$ & $19.77 \pm 0.24^{b}$ \\
\hline & 0.5 & $11.02 \pm 0.07^{b}$ & $9.35 \pm 0.32^{c}$ & & 0.5 & $11.25 \pm 0.4^{c}$ & $17.02 \pm 0.22^{c}$ \\
\hline & 1 & $11.02 \pm 0.65^{b}$ & $10.18 \pm 0.6^{b}$ & & 1 & $13.72 \pm 0.72^{a}$ & $23.21 \pm 0.17^{a}$ \\
\hline & 2 & $11.02 \pm 0.17^{b}$ & $9.12 \pm 0.06^{c}$ & & 2 & $11.98 \pm 0.4^{b}$ & $19.07 \pm 0.26^{b}$ \\
\hline \multirow{5}{*}{0.1} & 0 & $10.26 \pm 0.53^{c}$ & $10.02 \pm 0.53^{c}$ & \multirow{5}{*}{0.1} & 0 & $9.41 \pm 0.53^{d}$ & $9.41 \pm 0.53^{d}$ \\
\hline & 0.1 & $11.02 \pm 0.35^{\mathrm{ab}}$ & $9.632 \pm 0.15^{d}$ & & 0.1 & $17.2 \pm 0.05^{b}$ & $17.2 \pm 0.05^{b}$ \\
\hline & 0.5 & $11.79 \pm 0.16^{a}$ & $9.25 \pm 0.03^{c}$ & & 0.5 & $19.8 \pm 0.31^{\mathrm{a}}$ & $19.8 \pm 0.31^{a}$ \\
\hline & 1 & $12.23 \pm 0.53^{a}$ & $10.42 \pm 0.08^{b}$ & & 1 & $15.25 \pm 0.5^{c}$ & $15.25 \pm 0.5^{c}$ \\
\hline & 2 & $6.78 \pm 0.33^{d}$ & $11.12 \pm 0.4^{a}$ & & 2 & $15.2 \pm 0.06^{c}$ & $15.2 \pm 0.06^{c}$ \\
\hline \multirow{5}{*}{0.5} & 0 & $25.02 \pm 0.22^{c}$ & $9.35 \pm 0.19 d$ & \multirow{5}{*}{0.5} & 0 & $10.89 \pm 0.22^{e}$ & $9.35 \pm 0.19 \mathrm{e}$ \\
\hline & 0.1 & $32.11 \pm 1.01^{a}$ & $8.88 \pm 0.12^{d}$ & & 0.1 & $19.8 \pm 0.19^{c}$ & $19.8 \pm 0.08^{c}$ \\
\hline & 0.5 & $18.02 \pm 0.69^{c}$ & $16.6 \pm 0.5^{b}$ & & 0.5 & $25.32 \pm 0.32^{a}$ & $25.32 \pm 0.3^{a}$ \\
\hline & 1 & $32.23 \pm 0.11^{a}$ & $9.47 \pm 0.14^{c}$ & & 1 & $20.12 \pm 0.53^{b}$ & $20.12 \pm 0.12^{b}$ \\
\hline & 2 & $17.23 \pm 0.37^{\mathrm{e}}$ & $22.2 \pm 0.3^{a}$ & & 2 & $18.32 \pm 0.08^{d}$ & $18.32 \pm 0.03^{d}$ \\
\hline \multirow{5}{*}{1} & 0 & $15.15 \pm 0.35^{d}$ & $9.67 \pm 0.35^{d}$ & \multirow{5}{*}{1} & 0 & $9.84 \pm 0.35^{d}$ & $9.67 \pm 0.02^{d}$ \\
\hline & 0.1 & $21.89 \pm 0.48^{a}$ & $9.04 \pm 0.02^{d}$ & & 0.1 & $19.2 \pm 0.27^{b}$ & $19.2 \pm 0.1^{b}$ \\
\hline & 0.5 & $21.56 \pm .0 .12^{b}$ & $11.17 \pm .0 .28^{d}$ & & 0.5 & $19.56 \pm .0 .12^{b}$ & $19.56 \pm .0 .08^{b}$ \\
\hline & 1 & $21.01 \pm 0.79^{a}$ & $13.7 \pm 0.55^{\mathrm{a}}$ & & 1 & $21.7 \pm 0.95^{a}$ & $21.7 \pm 0.72^{a}$ \\
\hline & 2 & $15.42 \pm 0.11^{c}$ & $10.17 \pm 0.15^{c}$ & & 2 & $17.09 \pm 0.27^{c}$ & $19.09 \pm 0.12^{c}$ \\
\hline \multirow{3}{*}{2} & 0 & $19.24 \pm 1.12^{\mathrm{a}}$ & $8.76 \pm 1.34^{a}$ & \multirow{3}{*}{2} & 0 & $9.52 \pm 1.71^{\mathrm{e}}$ & $8.76 \pm 0.67^{d}$ \\
\hline & 0.1 & $10.26 \pm 0.44^{d}$ & $14.8 \pm 0.67^{d}$ & & 0.1 & $19.2 \pm 0.2^{b}$ & $15 \pm 0.36^{c}$ \\
\hline & 0.5 & $12.02 \pm 0.1^{d}$ & $10.05 \pm 0.77^{a}$ & & 0.5 & $14.5 \pm 0.15^{d}$ & $16.21 \pm 0.07^{b}$ \\
\hline
\end{tabular}




\begin{tabular}{lllllll|}
\hline $\mathbf{1}$ & $12.23 \pm 0.22^{\mathrm{b}}$ & $10.08 \pm 0.28^{\mathrm{c}}$ & & $\mathbf{1}$ & $16.23 \pm 0.16^{\mathrm{c}}$ & $16.23 \pm 0.03^{\mathrm{b}}$ \\
\cline { 1 - 3 } $\mathbf{2}$ & $11.79 \pm 0.25^{\mathrm{c}}$ & $10.23 \pm 0.2^{\mathrm{c}}$ & $\mathbf{2}$ & $30 . \mathrm{d} \pm 0.12^{\mathrm{a}}$ & $35.5 \pm 0.12^{\mathrm{a}}$ \\
\hline
\end{tabular}

Table 4. The selected PGRs concentrations for modeling by ANN to predict their effects on the cichoric acid, chlorogenic acid, and caffeic acid content in leaf and root-derived callus from Lactuca undulata.

\begin{tabular}{|c|c|c|c|}
\hline \multirow[b]{2}{*}{ Explant } & \multicolumn{3}{|c|}{ PGRs(mg/L) } \\
\hline & Kin & 2,4-D & NAA \\
\hline \multirow{11}{*}{ Leaf derived callus } & 0 & 0 & 0 \\
\hline & 0 & 0.5 & 0 \\
\hline & 0.1 & 1 & 0 \\
\hline & 0.5 & 1 & 0 \\
\hline & 1 & 0.1 & 0 \\
\hline & 2 & 2 & 0 \\
\hline & 0 & 0 & 1 \\
\hline & 0.1 & 0 & 0.5 \\
\hline & 0.5 & 0 & 0.5 \\
\hline & 1 & 0 & 1 \\
\hline & 2 & 0 & 2 \\
\hline \multirow{11}{*}{ Root derived callus } & 0 & 0 & 0 \\
\hline & 0 & 1 & 0 \\
\hline & 0.1 & 0.1 & 0 \\
\hline & 0.5 & 1 & 0 \\
\hline & 1 & 0.1 & 0 \\
\hline & 2 & 2 & 0 \\
\hline & 0 & 0 & 1 \\
\hline & 0.1 & 0 & 0.5 \\
\hline & 0.5 & 0 & 0.5 \\
\hline & 1 & 0 & 1 \\
\hline & 2 & 0 & 2 \\
\hline
\end{tabular}


Table 5. Performance of the ANN model used to predict production of cichoric acid, chlorogenic acid, and caffeic acid. SSE: Sum Square Error and RE: Relative Error for dataset training and testing.

\begin{tabular}{|lllllll|}
\hline organ & output & Activation & Architecture & R2 & SSE & RE \\
& function & & & & \\
\hline \multirow{2}{*}{ Leaf derived callus } & Cichoric acid & tangent- sigmoid & $3-30-1$ & 0.87 & 0.16 & 0.125 \\
\cline { 2 - 7 } & Chlorogenic acid & tangent-tangent & $3-15-1$ & 0.68 & 0.203 & 0.232 \\
\cline { 2 - 7 } & Caffeic acid & tangent-tangent & $3-35-1$ & 0.72 & 0.21 & 0.317 \\
\hline \multirow{2}{*}{ Root derived callus } & Chlorogenic acid & tangent-tangent & $3-25-1$ & 0.97 & 0.076 & 0.027 \\
\cline { 2 - 7 } & Cichoric acid & tangent-tangent & $3-20-1$ & 0.8 & 0.157 & 0.191 \\
\cline { 2 - 7 } & Caffeic acid & sigmoid-sigmoid & $3-20-1$ & 0.93 & 0.066 & 0.017 \\
\hline
\end{tabular}

\section{Figures}

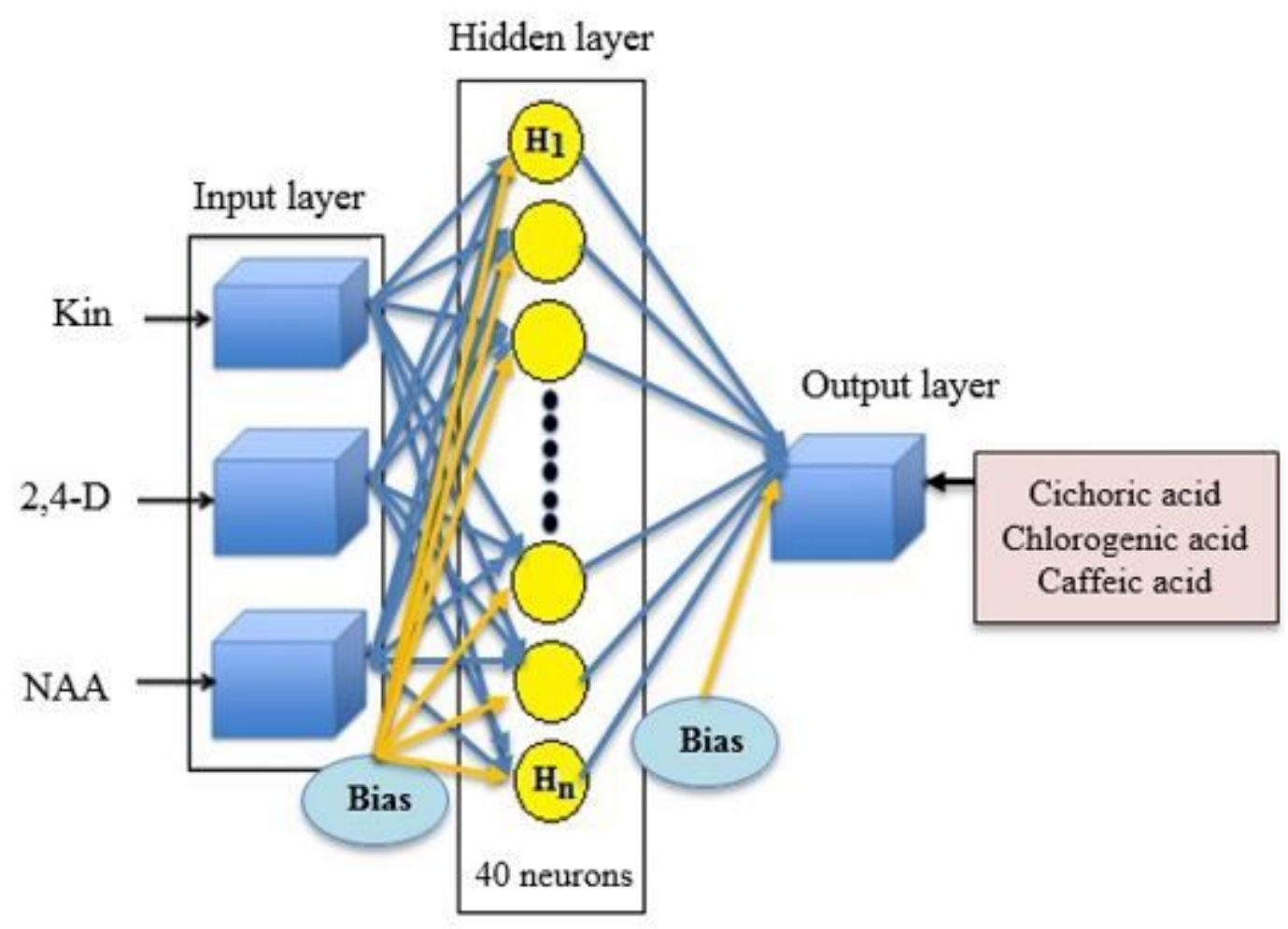

Figure 1 
Schematic model of Artificial Neural Network (ANN) used to predict the effect of PGRs (Kin, 2,4-D and NAA) on cichoric acid, chlorogenic acid, and caffeic acid production from leaf and root-derivated callus of L. undulata.

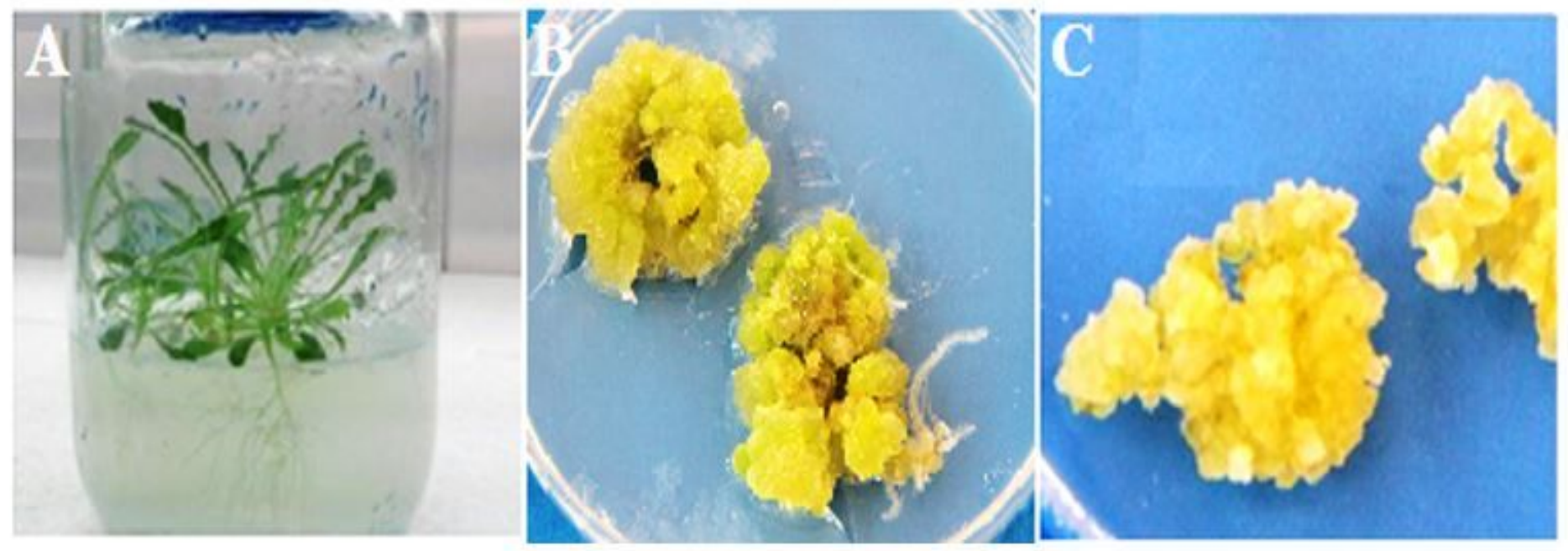

Figure 2

A) Sterile 2 months old Lactuca undulata seedling, B) Leaf-derived callus on $1 / 2$ MS medium supplemented with $0.5,0.5 \mathrm{mg} / \mathrm{L} 2,4-\mathrm{D}$ and Kin, C) Root-derived callus on $1 / 2 \mathrm{MS}$ medium supplemented with $0.5,0.5 \mathrm{mg} / \mathrm{L}$ NAA and Kin. 
Leaf derived callus

Root derived callus
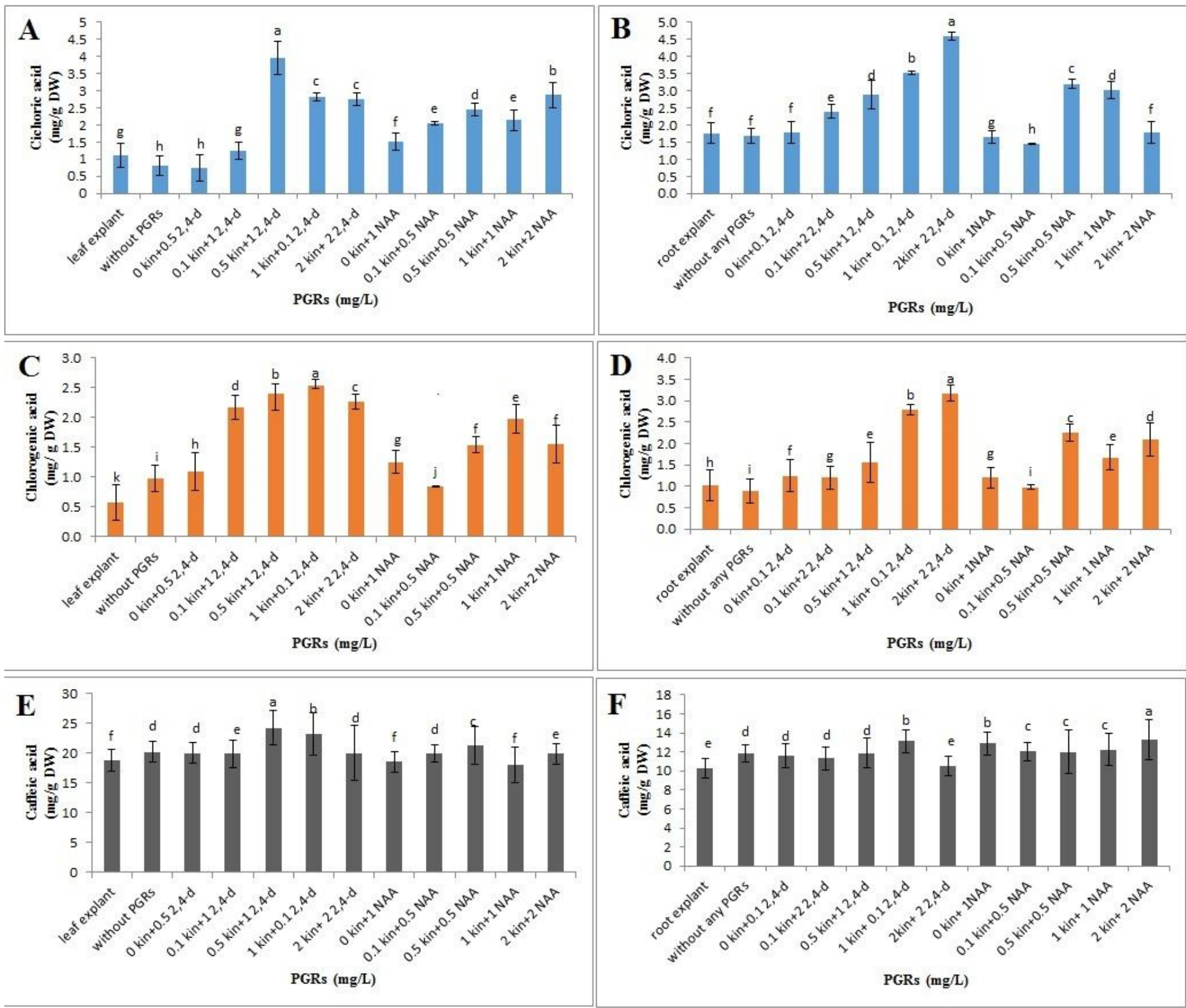

Figure 3

Cichoric acid (A, B), Chlorogenic acid (C,D) and Caffeic acid (E,F) contents in leaf and root-derived callus of $L$. undulata grown on $1 / 2$ MS medium supplemented with different concentrations of Kin in combination with 2,4- $\mathrm{D}$ and or NAA. Data are mean $\pm \mathrm{SE}$. The data were obtained from three independent experiments. Different letters within each column indicate significance at $\rho \leq 0.05$ by the least significant difference $($ LSD $)$ test $(n=3)$. 


\section{leaf derived callus}
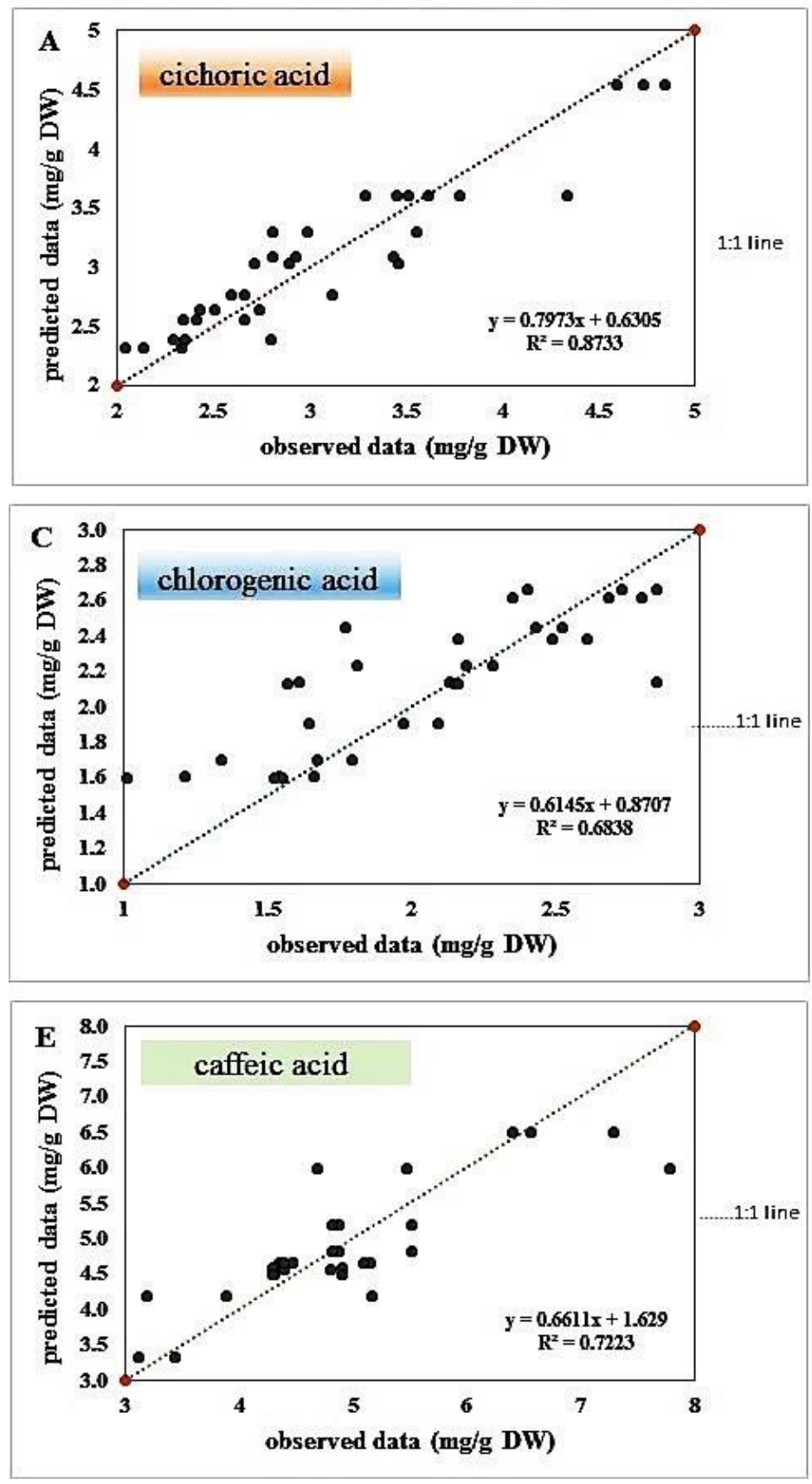

root derived callus
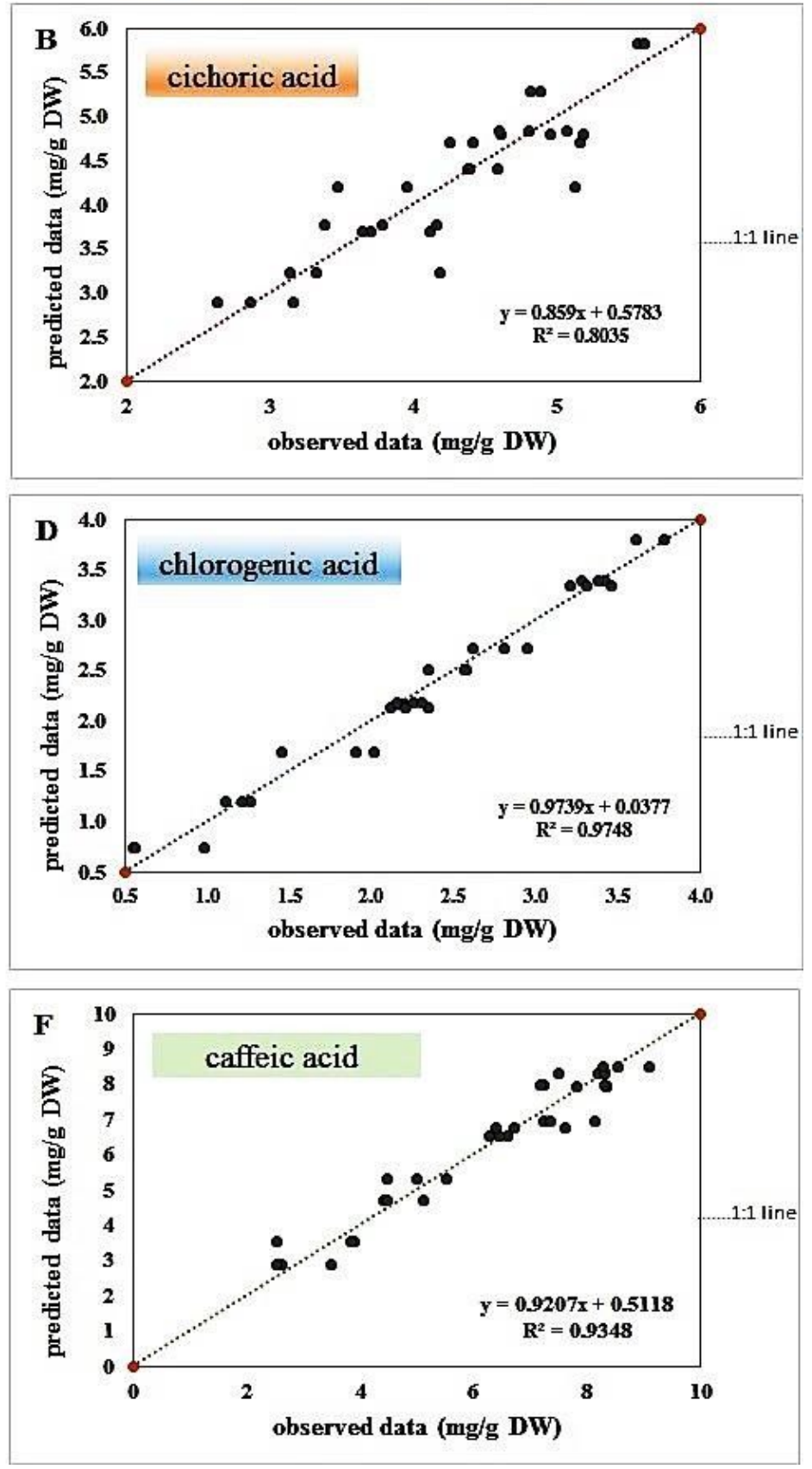

\section{Figure 4}

Correlation coefficient (R2) between experimental outputs (cichoric acid, chlorogenic acid, and caffeic acid production) versus ANN-predicted outputs in leaf (A) and root (B)-derived callus of Lactuca undulata. 